\title{
Comparing Social Virtual Worlds for Educational Purposes
}

\author{
Rosa Reis $^{1,2, *}$, Paula. Escudeiro ${ }^{1,2}$, Nuno. Escudeiro ${ }^{1}$ \\ ${ }^{1}$ Departamento Engenharia Informática, ISEP, Porto, 4200-072, Portugal \\ ${ }^{2}$ GILT- Graphics, Interaction and Learning Technologies, Porto, 4200-072, Portugal
}

\begin{abstract}
Over the last decade the interest in social virtual worlds as tools to improve the teaching/learning process and to stimulate knowledge, including the development of learning to learn autonomy, has greatly increased as a result of their promising potential. In the current work we introduce a concise definition of a social virtual world and make a comparative analysis between different virtual worlds based on Mannien's matrix. For this study, Second Life, Active Worlds and There were selected as they are the virtual environments most commonly addressed by the academic community. Finally, we discuss the potential of social virtual worlds for educational purposes.
\end{abstract}

Keywords Social Virtual World, MMOGs, Second Life, ActiveWorlds, There, Quality

\section{Introduction}

With the increase of the popularity of internet services together with its high potential to reach a large number of users, a new generation of applications is emerging on the Web: three dimensional (3D) multi-user interactive applications. These applications are characterized by sharing a 3D environment synthesized by the computer for multiple users. The virtual worlds are placed in the context of Virtual Reality. Virtual Reality - "computer-simulated environment, whether that environment is a simulation of the real world or an imaginary world[1]. According to Tiffin and Rajasingham[2], it provides some kind of immersion that involves the user in a fantasy only made possible by 3D digital technology. These worlds allow the creation of spaces through the metaphorical and prove a set of services. With the virtual worlds we can extend the low process of education, using not only the physical spaces but also the virtual. The flow of interactions is retained either graphically by means of the world itself, or in the form of movement evidencing the avatar's actions. In this context, the current paper aims to contribute to an increasing use of these environments, which can stimulate knowledge acquisition, including the development of learner autonomy.

Our research provides a definition of 3D virtual worlds, distinguishes different social virtual worlds (Second Life, Active Worlds and There), and makes a comparative analysis between them based on the matrix developed by Man

* Corresponding author:

rmr@isep.ipp.pt (Rosa Reis)

Published online at http://journal.sapub.org/edu

Copyright (C) 2011 Scientific \& Academic Publishing. All Rights Reserved nien in 2000[3]. In addition, the advantages of 3D social virtual worlds for educational purposes will be discussed.

In the future, the virtual worlds may provide a set of educational services including e-learning materials, course module materials, assignments and class sessions, communication between tutors and learners and assessment.

In this sense the paper is organized as follows: section 2 presents a definition of virtual world and describes some social virtual worlds; section 3 makes a comparative analysis between the social virtual world; finally, in the conclusions, the advantages

\section{Social Virtual Worlds}

The virtual world is far beyond a simple virtual environment. In the Real World, people are involved; people communicate with each other, interact with the world contributing to its permanent evolution. Based on these peculiar characteristics it is possible to obtain the following definition:

"A virtual world is a simulated persistent space based on the interaction by computer, inhabited by several users, who are represented by iconic images called avatars, who can communicate with each other and with the world in a synchronized way".

This definition refers to the key elements of virtual worlds:

Shared space: the world allows many users to participate at once. All the users have the feeling of being in the same place, room, land. The shared space is a common location where interactions occur. The place can be real or fictional but it should exhibit the same characteristics for all participants. 
Immersion and Interactivity: virtual worlds allow users to interact with the environment, to change, develop, build and submit content. "The user must feel immersed in the environment and fully engaged with the activities being undertaken. This is normally achieved through representation of the user and environment in world"[4].

Persistence: the world's existence continues regardless of whether individual users are logged in or not. The persistence of the world leads us to the immediacy feedback and synchronous use of the actions that take place in the world.

Immediacy: An immediate virtual world allows real-time interaction between the user and the world.

Socialization: interaction with others, working as teams to create communities.

These key elements contribute to represent different categories of information in a virtual world by means of three-dimensional objects that enable the development of a real life-like world.

The social virtual worlds differ from the Massive Multiplayer Online Games (MMOGS) mainly due to their strong socialization features. Moreover, MMOGS have predefined rules. These worlds are flexibly structured by open narratives. The players can act freely, talk, exchange information, and so on. Furthermore, the peculiar combination of the imaginary world (fantasy) with the social realism [4] is very clear.

The members of social virtual worlds live and prosper by using the social practices that they can find in offline environments, allowing their experience to be more realistic.

The users do not necessarily win or play a game, but socialize with other users.

The social worlds tend to be much less structured, providing an adjustment of the subject in accordance with reality, basic tools for the construction of the environment and the ability to host activities and events. In general, the social worlds operate more like communities and use elements of games, for instance Second Life, Active worlds, There, Club Penguin, Habbo Hotel, among others[1].

Looking at the different worlds, all have several technologies into a single platform: audio, video, webcam, text and voice chat (VOIP), graphical tools, scripting, web browser and, of course, avatars - the user's projection in the world. Combining these tools and the social aspects, it opens up the way for new perspectives, new ideas that will gradually allow new applications to be used more or less related to real economics.

From the wide range of tools available in the market, we have selected those that are usually addressed by the academic community, for the following reasons:

They have a great potential for integrating different technologies, allowing to present e-learning materials and e-content, narratives based on social interactions, to share documents and files, to hold meetings and events, and to create forums for sharing research findings and meetings with international colleagues.

They give users the ability to develop experiences that could be difficult in the real world.
They are safe places for students to learn by doing and enable them to work in collaborative teams. The ability to interact with one another simultaneously provides students with the opportunity to learn concepts not easily learned from a textbook [9].

Students are encouraged to engage in higher level cognitive thinking, such as interpreting, analysing, discovering.

\subsection{Second Life}

Second Life (SL)[11] is a 3D virtual platform of socialization, where it is possible to create a virtual character, called avatar, to reproduce real world daily actions, to accomplish fantastic feats like flying, change self-appearance in seconds and "tele-porting". The platform is an authoring environment allowing the user to build his world as a consistent project. For this purpose, SL contains tools for the design and for implementation. The objects and avatars' behavior can be controlled using the scripting language of the system, called Linden scripting Language (LSL) as we can observe in Figure 1.

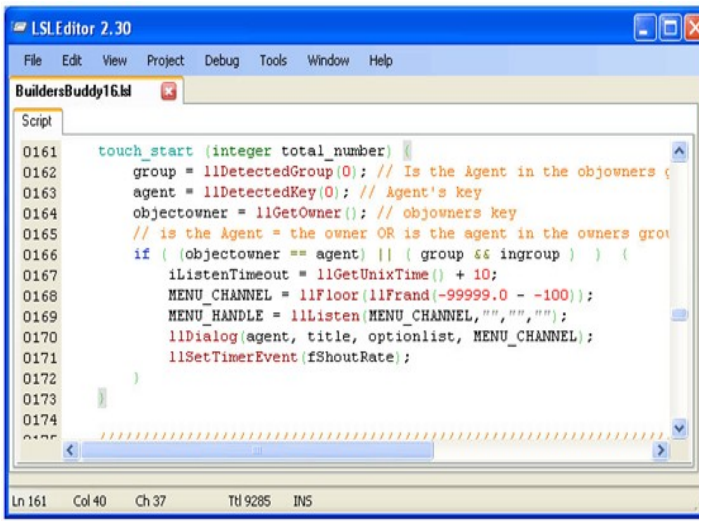

Figure 1. Linden Scripting Language (mundolinden.wordpress.com).

SL allows high levels of interaction, thanks to its potential for communication, collaboration and creation of virtual content. Interaction and interactivity are common in virtual worlds, together with persistence and immersion.

Communication is done through chat tools, voice, private messages and gestures. For voice communication, SL provides a system for the transmission of sound that reproduces the user's voice speaking to a microphone connected to the client computer at the avatar. The sound is transmitted and reproduced from the coordinated avatar in 3D space, thus only the avatars can hear your voice. Another form of interaction comes through gestures. Gestures animations are able to communicate feelings and to simulate an action. Second life includes a tool that lets users create their own gestures. SL has a monetary self-sufficient system, whose currency is the Linden Dollar, which has some value in the real world, and thereby the companies can make their businesses.

\subsection{Active Worlds}

Active Worlds (AW) (originally known as Alpha World) was officially opened on 27 July 1995, and it was created 
by Alpha World[10].

The AW is a virtual world with many independent worlds and universes, each with its own characteristics. It is a hybrid environment, composed by three-dimensional resources. Its main focus is on communication, providing its residents the opportunity to build something in the world, being owners of the building and also allowing the residents to designate levels of privacy and individual control over personal information. The privacy and identity design of both individual users and communities allow a degree of personal and social autonomy.

Four windows compose the browser interface of AW as we can observe in Figure 2. These provide a set of features that allow the user to build the virtual world in different languages such as English (default), Spanish, Portuguese, French, German, and Finnish.

This platform is divided into educational (Eduverse) and commercial universes. The worlds belonging to Eduverse are institutional worlds, namely universities or research projects, which were created with educational goals and are hosted in Host environment.

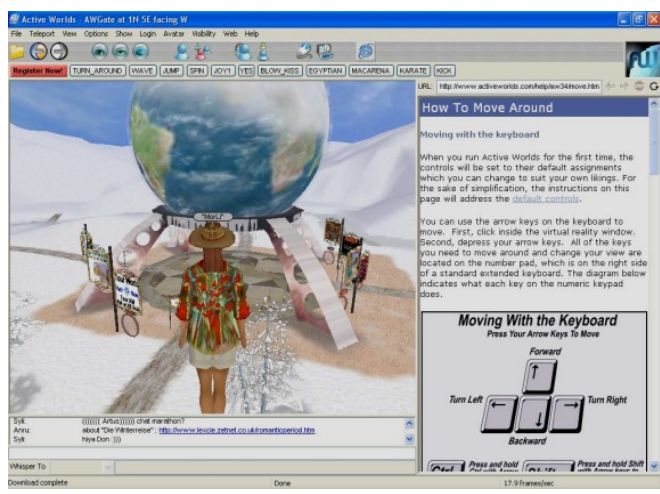

Figure 2. Interface of Active Worlds.

The universe of AW is a feature of online communities with thousands of users distributed in the virtual space, offering a range of possibilities, including making purchases online in 3D virtual space and talking with sellers by chat. The users can be tourists or residents. The tourists do not have access to all the resident's actions. They have only the right to plan and implement virtual worlds in certain regions from a database with all kinds of objects and respective functions.

\subsection{Croquet}

Opencroquet [12] is an open source platform for developing virtual worlds, has been implemented by Boston University (see Figure 3).

Derived from Squeak, has a network architecture "Peer-to-peer", which supports communication, collaboration, resource sharing, and synchronous computation between several users on multiple devices [16] .

This platform provides a dynamic environment where everything is an object of collaboration, which can be changed whenever you want. Communication between objects is based on the model of synchronization of message trans- mission. Their interactions are focused on sharing the three-dimensional space. Users not only communicate with each other by voice, but also have the ability to exchange documents, perform complex simulations, develop project plans and manage complex projects.

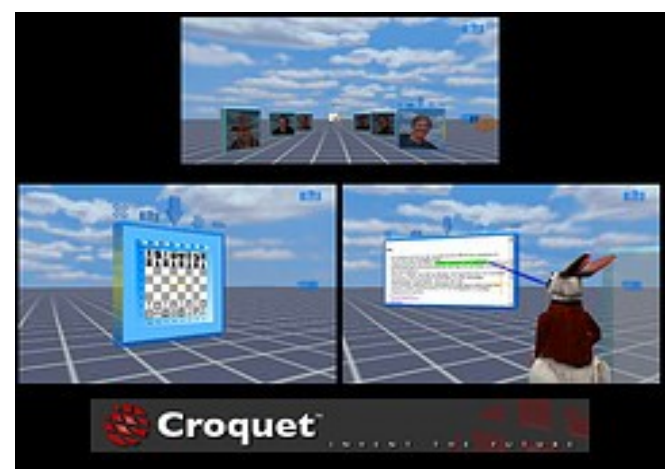

Figure 3. Croquet Platform.

In croquet the connection between virtual worlds $3 \mathrm{D}$ space is carried out via portals, similar to hyperlinks in Web pages. The portals are simply a 3D spatial connection between the spaces. A portal has a position and direction in the virtual world. These portals can be located in different places, allowing users to visit different parts of the virtual world, from several different portals

\section{Comparing Social Virtual World}

To improve the understanding of how the platforms, described in the previous section, can help us creating virtual worlds, it is necessary to focus on the characteristics of the design used to build the world. However, all the platforms share the same basic attributes (they are virtual, they mimic the real world or a part of it, and they have many simultaneous participants), often making it difficult to identify similarities and differences. So, to establish a comparison we have decided to analyse the various features of design in Second life, Active Worlds and Croquet.

The review process was developed in two main phases:

$>$ Identification and Classification of criteria

$>$ Evaluation of results

\subsection{Identification and Classification of Criteria}

To compare virtual worlds we started by identifying a set of criteria based on the Mannien's matrix[6]. As learning has a social dimension and its roots are linked to social interaction, the choice of this set of criteria allows us to have learning environments which contemplate the possibility of interaction, development and cooperation, besides forming a community of sharing, exposure of individuals' perspectives peer and joint initiative.

According to Mannien [3], the multi-user environments enable the occurrence of direct or indirect interactions between users, usually held in the form of cooperation and collaboration. In this sense the evaluation criteria will reflect the idea of promoting the CSCL (Computer Supported 
Collaborative Learning). Can be defined as an educational strategy in which two or more subjects build their knowledge through discussion, reflection and taken decisions, and where computing resources act (between others...) as mediators of process of teaching and learning[14]. If we consider as design principle of virtual worlds the mix of interaction, function and structure, we can analyze which platforms allow students to take a variety of roles, participate in simulations, practice real life skills in virtual space and explore situations in which they could not participate safely and easily in the world. Therefore, these criteria were grouped into 7 main factors: realism in the world, the user's interface, communication, the avatar's characteristics, scalability and security and pedagogy. Each factor is constituted by a sub-set of features (see Table 1).

Table 1. Mannien's Matrix for the Relevant Value Assigned to Each VW

\begin{tabular}{|c|c|c|c|}
\hline Criteria & $\mathbf{A W}$ & SL & Croquet \\
\hline \multicolumn{4}{|l|}{ 1.Realism of world } \\
\hline Online Interaction & 75 & 100 & 75 \\
\hline Existence of interactive objects & 100 & 100 & 75 \\
\hline Physical Models & 75 & 100 & 75 \\
\hline Speed of dynamic objects and the world & 75 & 100 & 75 \\
\hline Dynamic Scenarios & 75 & 100 & 75 \\
\hline AI in the world & 0 & 75 & 0 \\
\hline Evolution autonomous & 75 & 100 & 75 \\
\hline Presence of sociability & 100 & 100 & 100 \\
\hline Resemblance to the real world & 75 & 100 & 25 \\
\hline \multicolumn{4}{|l|}{ 2. User Interface } \\
\hline Navigation and control & 75 & 75 & 75 \\
\hline Control and mouse & 75 & 75 & 75 \\
\hline Support & 100 & 100 & 75 \\
\hline \multicolumn{4}{|l|}{ 3. Communication } \\
\hline Áudio & 100 & 100 & 100 \\
\hline Vídeo & 100 & 100 & 100 \\
\hline Text & 100 & 100 & 100 \\
\hline \multicolumn{4}{|l|}{ 4. Avatar } \\
\hline Complex & 75 & 100 & 25 \\
\hline Configurable & 100 & 100 & 75 \\
\hline Development & 100 & 100 & 75 \\
\hline Interaction & 75 & 100 & 100 \\
\hline Body language & 75 & 100 & 100 \\
\hline \multicolumn{4}{|l|}{ 5. Scalability } \\
\hline Distributes by multiple servers & 25 & 75 & 25 \\
\hline Limit creation of objects by user & 25 & 100 & 25 \\
\hline Limito of the world space & 75 & 75 & 25 \\
\hline Creation of users & 100 & 100 & 100 \\
\hline Limitation of languages & 75 & 75 & 25 \\
\hline Possibility of externs links & 75 & 100 & 75 \\
\hline \multicolumn{4}{|l|}{ 6. Security } \\
\hline Right on digital creations & 75 & 100 & 25 \\
\hline Security for the avatar & 75 & 75 & 75 \\
\hline Possibility of Paypal & 0 & 100 & 0 \\
\hline \multicolumn{4}{|l|}{ 7. Pedagogy } \\
\hline King of learning & 75 & 75 & 25 \\
\hline Teaching models & 100 & 100 & 0 \\
\hline
\end{tabular}

After identifying the criteria that best characterizes objectively the virtual worlds to be studied, we signed weights to each criteria. Each criteria was assigned a weight from 0 to $100 \%$ according to their relevance in the virtual world. The numerical values are assigned a qualitative equiva- lence:

0 - Not Applicable; 25 - Shortly applicable; 75 - Apply enough; 100 - Fairly applicable;

The aim is to know what are the main features of each virtual world because we need a virtual world for educational purposes. We know that there won't be one immediate solution that meets all our criteria, but for a product to be acceptable, it must have at least $80 \%$ of satisfactory results in assessments, a proportion that is set by the examiner, depending on your needs[8]. Thus, we want to identify the virtual worlds platforms, which allow us to build worlds where educators and students easily create new content and that make it possible to assess the students' progress, stimulating collaborative work

Once the comparison matrix was constructed, a weight was given to each criteria, and its value depends on its relevance in the virtual world to be analysed (Table 1).

The results have been achieved through an observation of applications in specific domains (sciences education, ecommerce, entertainment) existing in these virtual worlds platforms; and by developing small objects, adding objects and customizing the space of virtual world.

After we fulfil the matrix, we need calculate the percentage of compliance of each factor. These values were calculated based on QEF (Quantitative evaluation Framework) developed by Escudeiro[15]. This framework evaluates the system quality based on the standard of reference ISO $9126[16]$ and measures the quality relatively to hypothetical ideal system whose quality is assumed to be $100 \%$. If all criteria have a percentage of 100 , we can say that is an ideal platform for developing applications for education. It is calculated by the following formula:

$$
\text { Factor }_{n}=\frac{1}{\sum_{m} p r_{m}} \times \sum_{n}\left(p r_{m} \times p c_{m}\right)
$$

Where, the $\mathrm{m}$ is the number of relevance criteria to the factor in analysis; $\mathrm{pr}_{\mathrm{m}}$ is the weight of criteria $\mathrm{m}$ (in this 10) and $\mathrm{pc}_{\mathrm{m}}$ is the percentage of compliance with the criteria. For example:

FRealism of world $(\mathrm{AW})=1 / 90 *(10 * 0,75+10 * 1+$ $10 * 0,75+10 * 0,75+10 * 0,75+10 * 0+10 * 0,75+10 * 1+$ $10 * 0,75)=83,3$

Table 2. Percentage Obtained for Each Factors

\begin{tabular}{|c|c|c|c|}
\hline Factors & AW & SL & Croquet \\
\hline Realism of world & 83,3 & 97 & 63,8 \\
\hline User interface & 83,3 & 83,3 & 75 \\
\hline Communication & 100 & 100 & 100 \\
\hline Avatar & 85 & 95 & 75 \\
\hline Scalability & 83,3 & 97 & 45,8 \\
\hline Pedagogy & 87,5 & 87,5 & 12,5 \\
\hline
\end{tabular}

\subsection{Evaluation of Results}

The comparative study evidences a large homogeneity at the communication and interface levels, due to the nature of socialization and the problems that still exist at the usability (see Figure 4).

All the 3 worlds tested have weaknesses at the level of 
scalability, due to restrictions of space and objects to the creation of the world, and also in scripting language. The world created by the user (avatar) is not as real as it could be.

Distinguishing these 3 environments as the best and worst could be a difficult task as it depends on the user's intentions and expectations. For instance, Second Life has a higher success than Active Worlds; perhaps, today there is more mutual community awareness than when Active Worlds gave the first steps. When Active Worlds was developed the news spread by e-mail, static web pages;

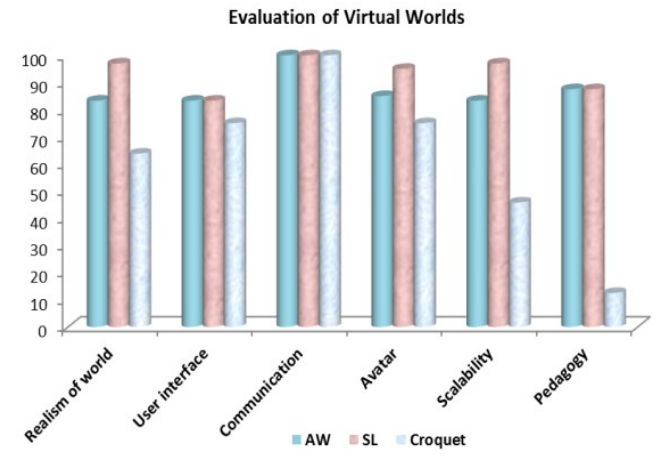

Figure 4. Evaluation of virtual worlds

Second Life appeared when people were more closely interlinked through blogs and other social networking devices, and as a consequence the new topics of interest tend to spread more rapidly. "Second Life is a unique digital world that puts the tools in the hands of its residents.

Through a scripting language, embedded 3D design tools, an easy-to-use character creation system, and methods for exchanging data with the real world, Second Life allowing highly interactive learner-to-learner and amateur-to-amateur creation and education" [13].

This study allows observing that these platforms increase the importance of its use in education. The users can manipulate objects, build and collaborate with each other, discover new information and present information in new and meaningful ways, which allows students and teachers to:

"Engage in the process of teaching learning, building up a richer and more dynamic learning experience where they are preparing for further study with the content"[9].

Facilitate understanding of difficult concepts to comprehend and demonstrate in the real world because these worlds have the potential to be a useful educational tool for teaching and learning.

In these virtual worlds students can have active participation, building their knowledge through interaction between subject and object. In this perspective, virtual worlds allow the development of open learning environments. The contents are not pre-defined nor are the student's actions, giving students the control over the environment. These features allow the student to be:

Participatory -- students learn to work in teams, consolidating the concept of collective and individual and strengthening their self-respect and the respect of others.

Creative - students discover and create new knowledge from their experience
Innovative - students have the spirit of challenge.

However, it was not correct to say that these virtual worlds provide only benefits. They have disadvantages: for example, learners can become easily distracted; some time is needed to understand and learn how to efficiently use the virtual world.

\section{Conclusions}

The responsiveness of information and communication technologies has enabled us to create ever more real virtual worlds where similarities with the real world are obvious. Currently, the realism offered by most of the virtual worlds allows simulating real life situations.

From the implementation point of view, these worlds are dynamic and constantly growing both in terms of users as in terms of virtual space.

The core characteristic of virtual worlds - the existence of a community of users who interact with each other - is common to all the virtual worlds we have analysed. These communities are frequently highly heterogeneous groups including cultural, linguistic and geographical differences among its members. This heterogeneous setting can have a transformative role in generating innovation through the exchange of experience in the future[8].

The great power of socialization coming from here allows us to note that social virtual worlds have a great probability to be applied to the educational context specifically in E-learning. However, there are some research questions such as: How can E-learning evolve into virtual education? How should the design of a virtual classroom look like to effectively foster gains in learning? What factors can motivate teachers (mostly the elder) to use virtual worlds?

Our work is being used as a base for the identification of problems arising in the specification of virtual worlds. After this, we will develop a virtual world model, aiming to improve and simplify the virtual world's design process. The model will use engineering software techniques; its main contributions shall include a rich interaction framework enabling computer-supported variations of the traditional activities (training, entertainment, and work, among others) and a deeper understanding of requirements, interaction and behaviours.

\section{REFERENCES}

[1] J. Isdale, "What is virtual Reality", September 1998; vr.isdale.com/WhatIsVR/.../WhatIsVR4.1.htm

[2] C. Tiffin, L. Rajasinghan, "In Search of the Virtual Class: Education. In an Information Society", London: Routledge, 1995

[3] T. Mannien," "Interaction in Networked Virtual Environments as Communicative Action - Social Theory and Multi-player Games", In proceedings of CRIWG2000 Workshop, October 18-20, Madeira, Portugal, IEEE Computer Society 
Press, 2000

[4] S. Freitas, "Serious Virtual Worlds: A Scoping Study", Bristol: JISC, 2008

[5] E. Castronova, "Synthetic Worlds", The University of Chicago Press,Chicago, 2004

[6] T. Manniem, "Rich Interaction Model for Game and Virtual Environment Design.”, PhD Thesis. Oulu University Press, Oulu, Finland, 2004

[7] B. Gros, "Knowledge Construction and Technology", Journal of Educational Multimedia and Hypermedia, vol. 11, no. 4, pp. 323-343, 2002

[8] C. Ondrejka, "Education Unleashed: Participatory Culture, Education, and Innovation in Second Life". Chapter of book The Ecology of Games: Connecting Youth, Games, and Learning. MIT, Press, p. 229-252, 2008

[9] Gros, B.(2002) "Knowledge Construction and Technology" Journal of Educational Multimedia and Hypermedia, vol. 11, no. 4 , pp. $323-343$

[10] www.activeworlds.com
[11] www.secondlife.com

[12] http://chris.superuser.com.au/virtual-worlds-croquet-secondli fe-opensim

[13] V.Stevens, "Second Life and Online Collaboration Through Peer Distributes Learning Networks, Proceedings of the METSMaCConference., Abu Dhabi, March 17-19,2007

[14] MINERVA, Núcleo Ue - Minerva - Universidade de Évora. Aprendizagem colaborativa assistida por computador. Disponível em: http://www.minerva.uevora.pt/cscl/. Acesso em: 05 setembro de 2003

[15] Escudeiro, P. "X-Tec Model and QEF Model: A case study". In T. Bastiaens \& S. Carliner (Eds.), Proceedings of World Conference on E-Learning in Corporate, Government, Healthcare, and Higher Education 2007 (pp. 258-265). Chesapeake, VA: AACE

[16] Onyesolu, M.O. "Virtual reality laboratories: The pedagogical effectiveness and use in obtaining cheap laboratories using the computer laboratory", Journal of Science Engineering and Technology, Vol. 16, No.1, (March 2009) 8679-8689, ISSN 1117-4196. 